\title{
Using upper-air conditions to estimate South Gascade Glacier (Washington, U.S.A.) summer balance
}

\author{
Lowell A. Rasmussen, Howard B. Conway \\ Department of Earth and Space Sciences, University of Washington, Box 351310, Seattle, Washington 98195-1310, U.S.A. \\ E-mail:lar@geophys.washington.edu
}

\begin{abstract}
A simple model uses once-daily meteorological values in the U.S. National Centers for Environmental Prediction and U.S. National Center for Atmospheric Research (NCEP-NCAR) re-analysis database to estimate summer balance of South Cascade Glacier, Washington, U.S.A., each year over 1959-99. The rms error, $0.30 \mathrm{~m}$ w.e. $\left(r^{2}=0.71\right)$, is comparable to measurement error. The model relates summer balance linearly to temperature $T>0{ }^{\circ} \mathrm{C}$ at $2000 \mathrm{~m}$ and to snow flux at $1650 \mathrm{~m}$, the altitudes in recent years of the equilibrium line and terminus. The snow flux is the product of the humidity and westerly wind component at $850 \mathrm{hPa}$ when temperature $T<+2{ }^{\circ} \mathrm{C}$ at $1650 \mathrm{~m}$. Temperatures are interpolated linearly between the 850 and $700 \mathrm{hPa}$ levels. Both the positive $2000 \mathrm{~m}$ temperature and the snow flux are summed from 26 April to 4 October. When the summer estimates are combined with those from a winter balance model using the same database, the rms error in estimating net balance is $0.40 \mathrm{~m}\left(r^{2}=0.81\right)$. The indicated sensitivities of balance to warming of $1^{\circ} \mathrm{C}$ are $-0.51 \mathrm{~m}$ for summer and $-0.24 \mathrm{~m}$ for winter. On the assumption that the total $-0.75 \mathrm{~m}^{\circ} \mathrm{C}^{-1}$ sensitivity exists at all altitudes, a warming of only $0.7^{\circ} \mathrm{C}$ would be sufficient to overcome the $1986-98$ average net balance $+0.5 \mathrm{~m}$ at the top of the glacier.
\end{abstract}

\section{INTRODUCTION}

Many previous studies of summer balance have used meteorological observations on or adjacent to the glacier itself undertaken specifically for those studies, or from an official weather station at some distance from the glacier, usually at lower altitude. Some apply rigorous physical principles to calculating ablation; others relate it to accumulated positive temperature during the ablation season. Recent examples of these approaches are described in Braithwaite and Zhang (2000), Oerlemans (2000) and Torinesi and others (2002), which give numerous references to earlier work. Hodge and others (1998) examined correlations of South Cascade Glacier (Washington, U.S.A.) seasonal mass balances over 1966-95 with four different measures of large-scale patterns of atmospheric circulation and of sea surface temperature: four measures correlated significantly with winter balance, but only one, sea surface temperature in the equatorial Pacific, correlated with summer balance $\left(r^{2}=0.30\right)$.

Recent work has shown that upper-air data can provide a good estimate of conditions on glaciers. For example, temperature on Blue Glacier in the Olympic Mountains of Washington State (Fig. 1) is much better approximated by interpolating from a nearby radiosonde than by applying a lapse rate to measurements at a lowland station (Conway and others, 1995). A simple flux model that uses upper-air data estimates the winter balance of South Cascade Glacier with error $0.24 \mathrm{~m}$ (Rasmussen and Conway, 2001).

The principal objective of this study is to investigate the use of upper-air variables routinely measured and archived in the U.S. National Centers for Environmental Prediction and U.S. National Center for Atmospheric Research (NCEP-NCAR) re-analysis database for estimating the sum- mer balance of South Cascade Glacier. Another objective is to combine summer balance $b_{\mathrm{s}}$ estimates with those of winter balance $b_{\mathrm{w}}$ and estimate net balance from $b_{\mathrm{n}}=b_{\mathrm{w}}+b_{\mathrm{s}}$, in which $b_{\mathrm{s}}$ is defined to be a negative quantity. A third is to demonstrate the effect of a hypothetical warming of the atmosphere on each of the balance components. Here, all balance values are in meters water equivalent, abbreviated to $\mathrm{m}$.

Two summer balance models are presented. The first simply relates $b_{\mathrm{s}}$ linearly to daily measurements of upperair temperature at the equilibrium-line altitude (ELA) of the glacier. A second, which offers a slight improvement, also uses upper-air winds and humidity to estimate the effects of summer snowfall.

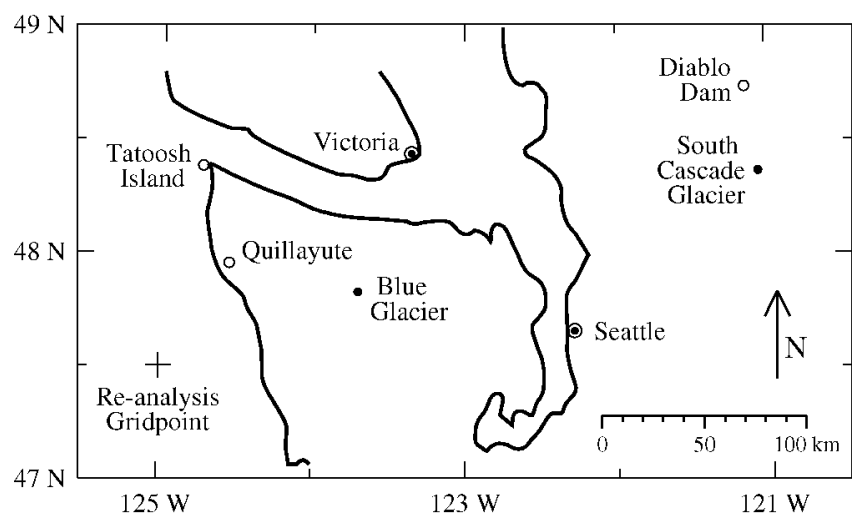

Fig. 1. Northwestern Washington State. The U.S. National Weather Service radiosonde was at Tatoosh Island prior to 1 August 1966 and at Quillayute afterward. The heavy curve is the smoothed coastline. 


\section{SOUTH GASGADE GLAGIER}

South Cascade Glacier $\left(48.36^{\circ} \mathrm{N}, 121.06^{\circ} \mathrm{W}\right)$ is a small, north-facing, temperate glacier on the crest of the North Cascade Range of northwestern Washington, $250 \mathrm{~km}$ from the Pacific Ocean (Fig. 1). It has an altitude range 1630$2130 \mathrm{~m}$ and an area of $2.0 \mathrm{~km}^{2}$. Most precipitation on the glacier falls as snow, with $\approx 3 \mathrm{~m}$ accumulating each winter at the head of the glacier. Annual ablation at the terminus usually exceeds $8 \mathrm{~m}$.

The glacier is not in equilibrium with the recent climate, having retreated and lost much mass over the past century (Miller, 1969; Krimmel, 2000). A glacier topography in equilibrium with the 1986-98 mass balance would occupy only about $30 \%$ of its 1999 extent (Rasmussen and Conway, 2001). Mean 1986-98 summer balance varied from about $-2.5 \mathrm{~m}$ at the head of the glacier to $-7.0 \mathrm{~m}$ at the terminus (Rasmussen and Conway, 2001, fig. 4). Over that period the ELA was 1990 m.

\section{DATA SOURCES}

The U.S. Geological Survey established a research program at South Cascade Glacier in the mid-1950s. Values of winter balance and net balance for each year, both averaged over that year's glacier topography, have been determined annually since 1958 (Krimmel, 2001). Here, revisions of previously published 1986-91 values (Krimmel, 2000) are used.

Winter balance at South Cascade Glacier is measured near the end of the accumulation season by probing at numerous points spanning the altitude range of the glacier and converting the snow depth to its w.e. amount by using an altitude variation of density obtained from direct measurements at usually one or two altitudes. Net balance is measured at the end of the ablation season by using the previous summer surface as the reference. In early years net balance was measured at several stakes in holes drilled into the ice, afterward at a smaller number of stakes in positions learned in the early years to be strategic for determining the altitude variation over the whole glacier. In recent years three or four ablation stakes were installed and snow depth was probed at 20-50 sites (Krimmel, 2000). Summer balance is calculated as the difference between the net balance and winter balance.

The U.S. NationalWeather Service operated a radiosonde station with twice-daily soundings from 1948 until 1 August 1966 at Tatoosh Island, 275 km west of South Cascade Glacier, and since then at Quillayute, about $50 \mathrm{~km}$ south and $10 \mathrm{~km}$ east of Tatoosh Island (Fig. 1). Soundings measure temperature, humidity and wind at many levels in the atmosphere. The NCEP-NCAR re-analysis database consists of radiosonde observations, along with surface and satellite observations, systematically merged into a set of internally consistent meteorological values, with 6 hour resolution since 1948, interpolated at several vertical levels to a regular grid spanning the entire Earth (Kalnay and others, 1996).

The re-analysis data used here were obtained from NCAR in April 2001. Data include temperature, winds and humidity measured at 1200 UTC (Universal Time Coordinated; 0400 local time) over 1959-99, at $850 \mathrm{hPa}(\approx 1450 \mathrm{~m})$ and $700 \mathrm{hPa}(\approx 3000 \mathrm{~m})$, at a gridpoint at $47.5^{\circ} \mathrm{N}, 125^{\circ} \mathrm{W}$, which is $310 \mathrm{~km}$ west-southwest of the glacier (Fig. 1). Data from that gridpoint were acquired because it is nearest Quillayute, the radiosonde station from which data were used in earlier work on a closely related subject (Rasmussen

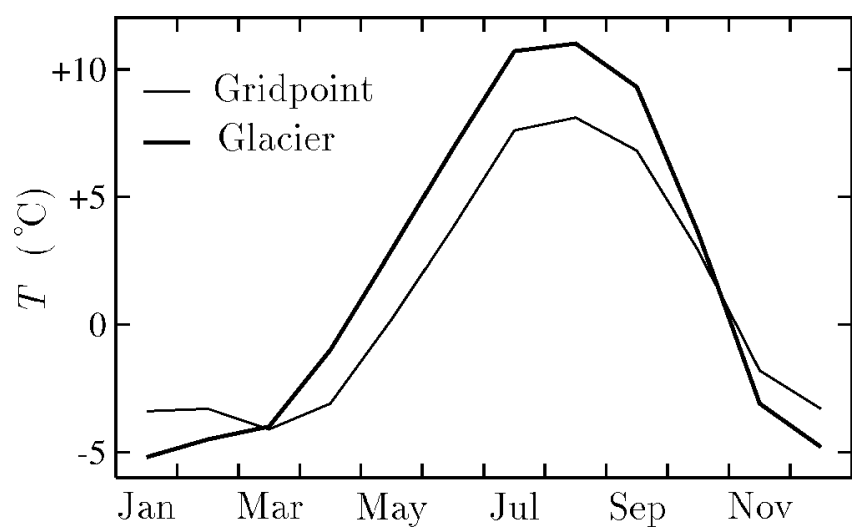

Fig. 2. Seasonal variation of temperature at South Cascade Glacier and at re-analysis gridpoint $47.5^{\circ} \mathcal{N}, 125^{\circ} \mathrm{W}$. The value at the gridpoint is the 1959-99 mean of the temperature interpolated at $2000 \mathrm{~m}$ between the 850 and $700 \mathrm{hPa}$ levels in the NCEP-NCAR re-analysis database. Temperature at the glacier is calculated by applying to it the horizontal gradient of mean monthly 850 hPa temperature (United States Navy, 1966).

and others, 2001). Horizontal variations of upper-air temperature were scaled from an upper-air atlas (United States Navy, 1966), which showed that the temperature gradient swings from south-southwest in winter to east-southeast in summer and doubles in magnitude. Projection of the gradient on the distance between the glacier and the re-analysis gridpoint yields an adjustment $\Delta T$, which is assumed to be constant over the altitude range of the glacier. Monthly mean 1959-99 temperatures at the gridpoint interpolated at $2000 \mathrm{~m}$ between the 850 and $700 \mathrm{hPa}$ levels, along with those estimated for the glacier, are shown in Figure 2.

\section{REGIONAL GLIMATOLOGY}

Northwestern Washington has mild, wet winters and mild, dry summers. The four wettest months, November-February, account for about $57 \%$ of the annual precipitation, and the four driest, June-September, for only about $11 \%$. Nearly all precipitation in this region is produced by extratropical cyclones from the Pacific Ocean, often occurring in rapid succession in winter and only occasionally in summer. Convective storms are uncommon, even in summer. The north-south-trending Cascade Range is an effective climate barrier that delineates the humid marine region to the west from the arid continental region to the east.

\section{ESTIMATING SOUTH GASGADE GLAGIER SUMMER BALANGE}

\subsection{An ablation formulation, the $T$ model}

Of the upper-air variables examined, temperature is the one that correlates best with summer balance (Table 1). In a simple linear relation, balance in year $j$ is estimated from

$$
b_{\mathrm{s}, j}^{*}=\alpha_{1} \bar{T}_{\mathrm{ELA}, j}+\gamma_{1}
$$

in which the constant term $\gamma_{1}$ presumably accounts for radiative melt in the absence $(T \leq 0)$ of turbulent exchange. Here $\bar{T}_{\text {ELA }}$ is the temperature interpolated at $2000 \mathrm{~m}$ (the ELA in recent years) between the 850 and $700 \mathrm{hPa}$ levels at the re-analysis gridpoint, adjusted to the location of the glacier by the horizontal gradient (Fig. 2) and averaged 
Table 1. Correlations over 1959-99

\begin{tabular}{clc}
\hline & \multicolumn{1}{c}{ Variables } & $r$ \\
\hline$b_{\mathrm{s}}$ & $\bar{T}_{\text {ELA }}$ & -0.81 \\
$b_{\mathrm{s}}$ & $\bar{T}_{\text {ELA }}^{+}$ & -0.79 \\
$b_{\mathrm{s}}$ & Number of days with low RH & -0.70 \\
$b_{\mathrm{s}}$ & Number of early days with low RH & -0.60 \\
$b_{\mathrm{s}}$ & Number of late days with low RH & -0.43 \\
$b_{\mathrm{s}}$ & RH & 0.69 \\
$b_{\mathrm{s}}$ & $\bar{f}$ & 0.69 \\
$\bar{T}_{\mathrm{ELA}}$ & RH & -0.78 \\
$\bar{T}_{\mathrm{ELA}}$ & Number of days with low RH & 0.72 \\
$\bar{T}_{\mathrm{ELA}}$ & Number of dry days at Diablo Dam & 0.65 \\
$\bar{f}$ & $\bar{T}_{\text {ELA }}^{-}$ & -0.78 \\
$\bar{f}$ & Number of days with $T_{\text {ELA }}<0$ & 0.89 \\
& & \\
\hline
\end{tabular}

Notes: Summer balance $b_{\mathrm{s}}$ is a negative quantity. Variables $\bar{T}_{\mathrm{ELA}}, \mathrm{RH}$ and $\bar{f}$ are averaged over days 116-277 (26 April - 4 October) except that "early" indicates only the first 60 days and "late" only the last 60 . The degree-day average $\bar{T}_{\mathrm{ELA}}^{+}$is formed from sum of only $T_{\mathrm{ELA}}>0$, and $\bar{T}_{\mathrm{ELA}}^{-}$from sum of only $T_{\text {ELA }}<0$. Low RH is $<0.65$. Diablo Dam dry days are overJulySeptember.

from day $t_{0}$ through day $t_{1}$. Model parameters $\left(t_{0}, t_{1}, \alpha_{1}\right.$ and $\gamma_{1}$ ) were determined empirically to minimize the rms error $\epsilon_{\mathrm{s}}$. Over the 41 years $j=1959, \ldots, 1999$, the rms of the residuals $b_{\mathrm{s}, j}^{*}-b_{\mathrm{s}, j}$ is $0.33 \mathrm{~m}$. Where the standard deviation of $b_{\mathrm{s}, j}$ is $\sigma=0.55 \mathrm{~m}$, the coefficient of determination $r^{2}=0.65$ is calculated from

$$
r^{2}=1-\left(\frac{\epsilon_{\mathrm{s}}}{\sigma}\right)^{2}
$$

Optimum start and end dates are $t_{0}=116$ (26 April) and $t_{1}=277$ (4 October), with $\alpha_{1}=-0.50$ and $\gamma_{1}=-0.67$. Over 1959-99, $\bar{T}_{\mathrm{ELA}}=7.8^{\circ} \mathrm{C}$ and $\bar{b}_{\mathrm{s}}=-3.18 \mathrm{~m}$. Because $\alpha<0$, the correlation between $\bar{T}_{\mathrm{ELA}}$ and $b_{\mathrm{S}}$ is negative, $r=-0.81$.

Forming a regression by summing $T_{\mathrm{ELA}}-T^{\prime}$ on only those days when it exceeds the threshold $T_{\mathrm{ELA}}>T^{\prime}$, such as in positive-degree-day models that use $T^{\prime}=0^{\circ} \mathrm{C}$, degraded results (Fig. 3d). Because summer balance at South Cascade Glacier consists of a large negative ablation component and a small positive accumulation component, the inclusion of negative temperatures in forming $\bar{T}_{\text {ELA }}$ presumably accounts for summer snowfall events. In addition, $T>$ 0 can sometimes occur low on the glacier, producing melt there, when $T_{\text {ELA }}<0$.

\subsection{An ablation-accumulation formulation, the $T, f$ model}

Snowfall can be approximated explicitly by taking it to be proportional to the snow flux $f$ when $T_{\text {TERM }}$ at the glacier terminus, about $1650 \mathrm{~m}$, is less than $+2^{\circ} \mathrm{C}$. The snow flux is given by

$$
f=\left\{\begin{array}{cc}
U R H & \left(U>0, T_{\text {TERM }}<+2{ }^{\circ} \mathrm{C}\right) \\
0 & \text { (otherwise) }
\end{array}\right.
$$

in which $0 \leq \mathrm{RH} \leq 1$ is the $850 \mathrm{hPa}$ relative humidity, and $U$ is the component of the wind in the empirically determined critical direction $\phi^{\prime}$. That is,

$$
U=\left|\vec{V}_{850}\right| \cos \left(\phi_{850}-\phi^{\prime}\right),
$$

where $\phi_{850}$ is the direction and $\left|\vec{V}_{850}\right|$ the speed in $\mathrm{m} \mathrm{s}^{-1}$ of the $850 \mathrm{hPa}$ wind. The wind, $\mathrm{RH}$, and $T_{\text {TERM }}$ are at the re-analysis gridpoint, with $T_{\text {TERM }}$ being interpolated between the 850

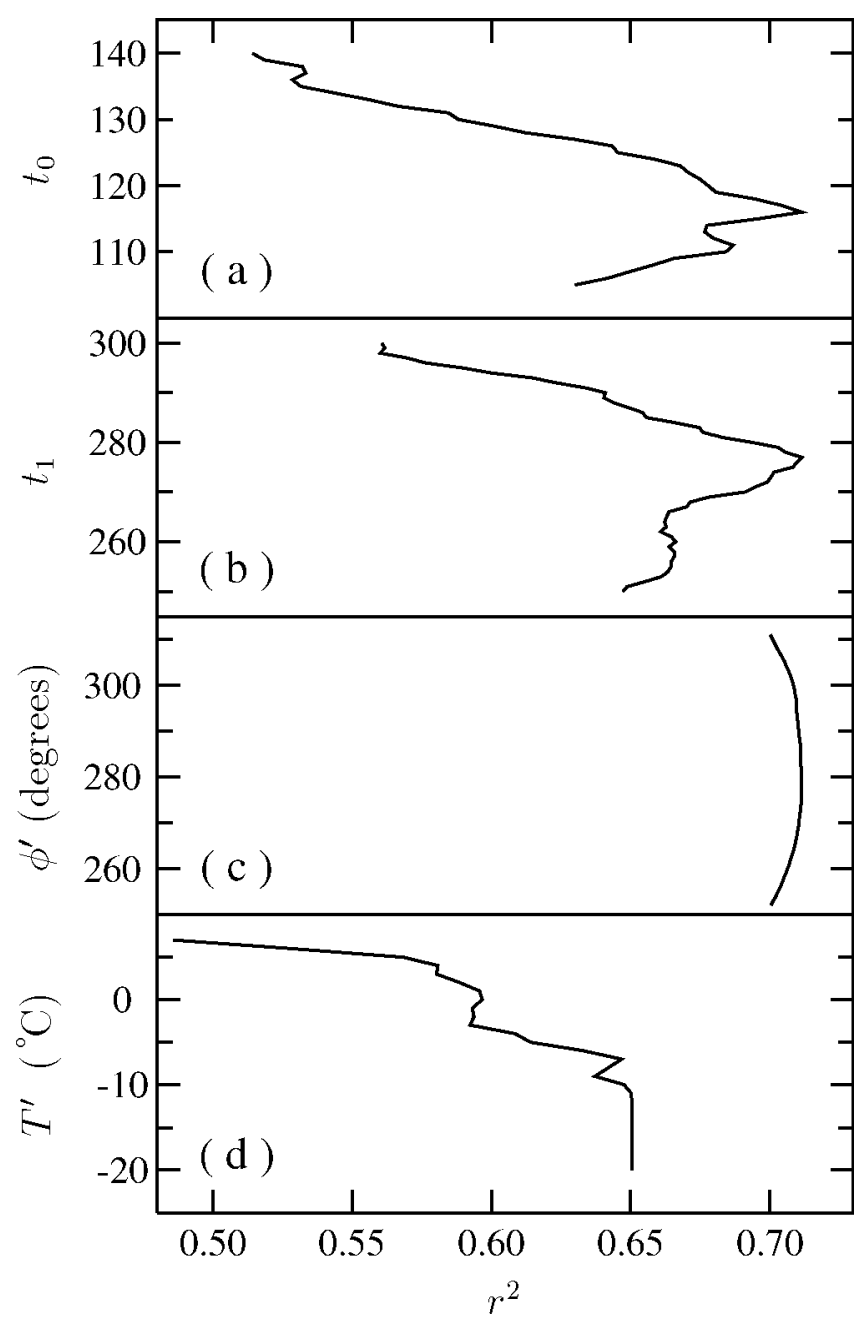

Fig. 3. Sensitivity of summer balance models to values of model parameters: (a) beginning date $t_{0}$ for temperature averaging; (b) ending date $t_{1}$ for temperature averaging; (c) critical direction $\phi^{\prime}$ for calculating $f$ (Equations (3) and (4)); (d) threshold temperature $T^{\prime}$ above which to sum $T_{\mathrm{ELA}}$ in Equation (1). As each parameter $(a-c)$ in the $T, f$ model (Equation (5)) is varied, the others are held at their optimum values: $t_{0}=$ 116 ( 26 April), $t_{1}=277$ ( 4 October) and $\phi^{\prime}=271^{\circ}$. The $T$ model (Equation (1)) differed only in having optimum $t_{1}=$ 279; its optimum $T^{\prime}$ being below the lowest $T_{\mathrm{ELA}}$ in the period of record indicates all $T_{\mathrm{ELA}}$ should be used in forming $\bar{T}_{\mathrm{ELA}}$.

and $700 \mathrm{hPa}$ levels and adjusted to the glacier by the difference $\Delta T$ (Fig. 2). The optimum $\phi^{\prime}=271^{\circ}$ is adopted from the results of running a winter balance model (Rasmussen and Conway, 2001) with 1200 UTC re-analysis data. Tests of the model using either RH or specific humidity (Rasmussen and others, 2001, table 4) indicate that $\mathrm{RH}$ gives better results, presumably because precipitation is a saturation phenomenon. Section 6 of that study also showed that the simple flux model gave better results than a two-dimensional mesoscale model. Another test showed that at five stations in the central Cascades of Washington over a 143 day period during the 1996/97 winter, it produced substantially better results than an advanced mesoscale precipitation model (Hayes and others, 2002, table 6).

The two-term model for summer balance, with both $T_{\text {ELA }}$ and $f$ averaged over days 116-277 (the optimum dates from the one-term model)

$$
b_{\mathrm{s}, j}^{*}=\alpha_{2} \bar{T}_{\mathrm{ELA}, j}^{+}+\beta_{2} \bar{f}+\gamma_{2},
$$




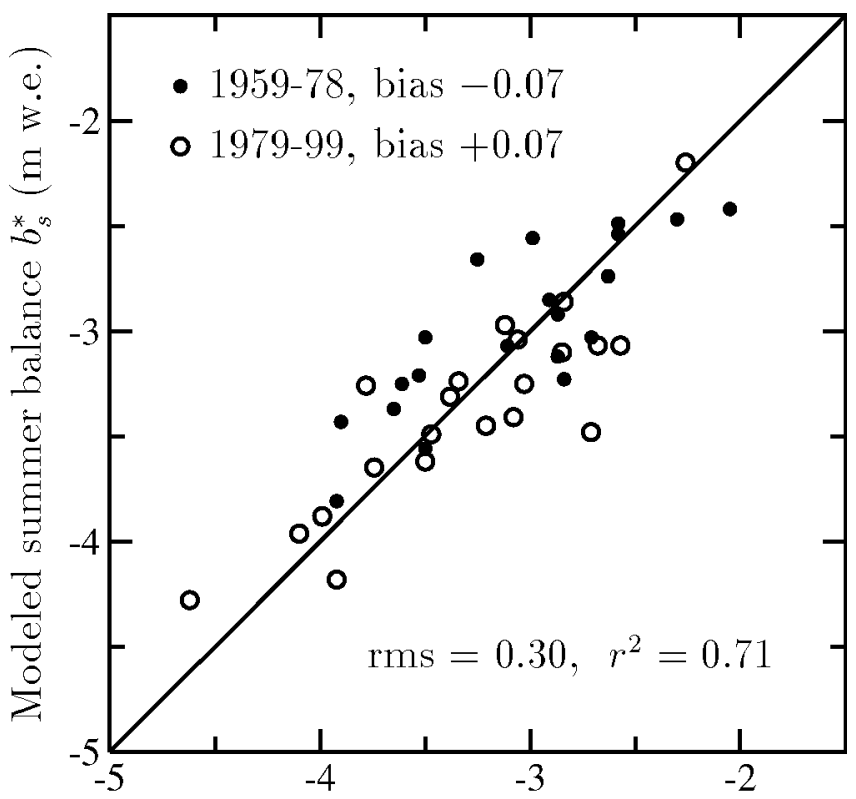

Observed summer balance $b_{s}$ (m w.e.)

\begin{abstract}
Fig. 4. Results from summer balance $T, f$ model (Equation (5)) over 1959-99, using $t_{0}=116$ ( 26 April), $t_{1}=277$ ( 4 October) and $\phi^{\prime}=271^{\circ}$. Residuals for 1959-78 (solid circles) have mean value $-0.07 \mathrm{~m}$ and for 1979-99 (open circles) have mean value $+0.07 \mathrm{~m}$.
\end{abstract}

has $\epsilon_{\mathrm{s}}=0.30 \mathrm{~m}$ and $r^{2}=0.71$. Introducing $f$ to account explicitly for accumulation relieves $T_{\mathrm{ELA}}$ of needing to do it, and results improve when $\bar{T}_{\text {ELA }}$ is formed from the sum of only $T_{\text {ELA }}>0$, which is represented by $\bar{T}_{\text {ELA. }}^{+}$The coefficients, again determined empirically to minimize the error, are $\alpha_{2}=-0.39, \beta_{2}=1.27, \gamma_{2}=-0.48$. Over 1959-99, $\bar{T}_{\mathrm{ELA}}^{+}=$ $8.1^{\circ} \mathrm{C}$ and $\bar{f}=0.37 \mathrm{~m} \mathrm{~s}^{-1}$ with $\phi^{\prime}=271^{\circ}$. Sensitivity of results to model parameters $t_{0}, t_{1}, \phi^{\prime}$ and $T^{\prime}$ (Fig. 3 ) is determined by varying each one experimentally while holding the others at their optimum values. The parameters are strongly orthogonal, with the apparent optimum value of one being markedly insensitive to the values adopted for the others.

Improvement of the $T, f$ model over the $T$ model (Equation (1)) is significant at the 0.01 level according to the statistical $F$ test. The 41 observed $b_{\mathrm{s}, j}$ and calculated $b_{\mathrm{s}, j}^{*}$ are compared in Figure 4.

\subsection{Correlation of summer balance with meteoro- logical variables}

Although both turbulent exchange and the downward longwave flux are increasing functions of $T_{\mathrm{ELA}}$, the models do not explicitly account for variations in solar radiation. High $T_{\mathrm{ELA}}$, however, is usually accompanied by clear weather with greater atmospheric transmittance (low $\mathrm{RH}$ ), which is indicated by the strong negative correlation between $T_{\mathrm{ELA}}$ and RH (Table 1) and the positive correlation with the number of days with low RH (below 0.65) and with the incidence of dry days at Diablo Dam, which is $40 \mathrm{~km}$ north of the glacier (Fig. 1). The $0.65 \mathrm{RH}$ threshold was also used to distinguish between wet and dry days in modeling precipitation in Colorado (Rhea, 1978) and in Washington (Rasmussen and others, 2001). In addition, the season of high $T_{\text {ELA }}$ is July and August (Fig. 2), when clear weather is most likely. Incoming solar radiation increases with high transmittance associated with clear weather, and by July and August much of the glacier surface has changed from high-albedo snow to low-albedo ice, thus permitting more of the received radiation to be absorbed.

Previous calculations (Rasmussen and Conway, 2001) show that about $9 \%$ of the total accumulation occurs during summer. The summer snow flux increases with the number of cold days in summer and also during cold summers, which is reflected by the positive correlation between $\bar{f}$ and the number of $T_{\text {ELA }}<0$ days and the negative correlation between $\bar{f}$ and $\bar{T}_{\text {ELA }}^{-}$(Table 1), which was calculated by averaging all $T_{\mathrm{ELA}}<0$ over the summer season. Summer balance becomes less negative as $\bar{f}$ increases, and that occurs with more negative temperatures.

Correlations of $b_{\mathrm{s}}$ with other upper-air variables are also shown in Table 1 . It correlates positively with $850 \mathrm{hPa}$ relative humidity $\mathrm{RH}$ and negatively with the number of days when $\mathrm{RH}$ is low. Correlation of $b_{\mathrm{s}}$ with the number of low$\mathrm{RH}$ days in spring $(r=-0.60)$ is stronger than with the number in late summer $(r=-0.43)$; albedo is lower in late summer, but sun angles are higher in spring. Correlations of $b_{\mathrm{s}}$ with $\bar{T}_{\mathrm{ELA}}$ and $\bar{T}_{\mathrm{ELA}}^{+}$are strongly negative.

\subsection{Distribution of errors}

There are several sources of error. The models only crudely represent the relevant physical processes and coarsely sample atmospheric conditions. They use data at only one geographic point, from only two vertical levels and only once a day. The model parameters, however, appear to be little affected by sampling error as shown by the split-sample tests detailed in the Appendix.

Determining summer balance from glacier observations is also subject to several sources of error. It is not measured directly, but is the difference between measurements of net balance and winter balance, which are both susceptible to sampling error in the horizontal. Braithwaite (1986) found a variance of $0.25 \mathrm{~m}$ in net balance measured over 1979-84 at three closely spaced stakes in the ablation zone of a glacier in southwest Greenland. Measuring winter balance is subject to the possibility of not probing exactly to the previous summer surface and of using imprecise density values to convert the thickness to a water equivalent amount. Undetected ablation after the last measurements of the season introduces error in determining net balance $b_{\mathrm{n}}$. The rms of errors that Krimmel (2000, p.77) estimated over 1986-91 are $\delta_{\mathrm{w}}=0.24 \mathrm{~m}$ for winter balance and $\delta_{\mathrm{n}}=0.23 \mathrm{~m}$ for net balance. On the assumption that the errors are uncorrelated, because the two balance components are independently measured, the error in summer balance $b_{\mathrm{s}}$ is $\delta_{\mathrm{s}}=$ $0.33 \mathrm{~m}$. That is, $\delta_{\mathrm{s}}^{2}=\delta_{\mathrm{n}}^{2}+\delta_{\mathrm{w}}^{2}$ (Bevington, 1969, p. 64).

\subsection{Effect of changing topography}

There is an incoherence between the glacier variable $b_{\mathrm{s}}$ and the upper-air variables $\bar{T}_{\text {ELA }}$ and $\bar{f}$ in Equations (1) and (5). Conditions aloft at the re-analysis gridpoint are unaffected by changes in the topography of South Cascade Glacier, but published glacier-total balance values describe the effect of climate on a varying glacier topography. Values of $b_{\mathrm{n}}$ and $b_{\mathrm{w}}$ were determined year by year over a glacier topography that was steadily losing area at low altitude, where both components are more negative than at higher altitude. The effect of loss of area in the region of strongly negative balance was offset slightly by the effect of thinning else- 
where, which lowered the surface along the vertical gradient of balance $\partial b / \partial z>0$.

Published values of $b_{\mathrm{n}}$ and $b_{\mathrm{w}}$ for the early years are less positive than they would have been if the $b_{\mathrm{n}}(z)$ and $b_{\mathrm{w}}(z)$ from which they were calculated had been integrated over the mean 1959-99 topography, and for the later years are more positive than they would have been if they had been integrated over the mean topography. In a definitive analysis of these effects, Elsberg and others (2001) found that the cumulative net balance reported over 1970-97 (-15 m) was $16 \%$ more positive than if the $b_{\mathrm{n}}$ curves had all been integrated over the 1970 topography. If the constant-topography values $\hat{b}_{\mathrm{n}}$ differed from the published $b_{\mathrm{n}}$ by an increment that grew steadily by a constant amount $\Delta b$ each year as the glacier shrank, the $\hat{b}_{\mathrm{n}}$ values for $1970,1971, \ldots$, 1997 would be

$$
\begin{aligned}
& b_{70}+\left(b_{71}-\Delta b\right)+\left(b_{72}-2 \Delta b\right)+\cdots+\left(b_{97}-27 \Delta b\right) \\
& =1.16(-15)=-17.4
\end{aligned}
$$

from which subtracting $b_{70}+b_{71}+\cdots+b_{97}=-15$ gives $\Delta b=+0.006 \mathrm{~m}$ each year. The effect of changing topography is reflected by the distribution of residuals (Fig. 4), with the mean value of $b_{\mathrm{s}}-b_{\mathrm{s}}^{*}$ over $1959-78$ being $-0.07 \mathrm{~m}$ and over 1979-99 being $+0.07 \mathrm{~m}$. That is, in the early years, when the glacier had more area at low altitude, the published $b_{\mathrm{s}}$ values were more negative on average than the model indicates; in the later years, when it had less area there, they were more positive. Most of the scatter between measured and estimated values, however, is due to imperfections in the model, error in meteorological data and error in the mass-balance measurements.

\section{ESTIMATING NET BALANGE}

Net balance $b_{\mathrm{n}}$ can be estimated by adding $b_{\mathrm{s}}^{*}$ from the $T, f$ model (Equation (5)) to estimates of $b_{\mathrm{w}}^{*}$ from the winter balance model (Rasmussen and Conway, 2001). When the models use data from the same re-analysis gridpoint over $1959-99, \epsilon_{\mathrm{s}}=0.30 \mathrm{~m}$ and $\epsilon_{\mathrm{w}}=0.29 \mathrm{~m}$, which yields $\epsilon_{\mathrm{n}}=$ $0.40 \mathrm{~m}$. This is less than the error if the residuals were uncorrelated (0.42) because of a slight negative correlation $(r=$ $-0.07)$ between $\epsilon_{\mathrm{s}}$ and $\epsilon_{\mathrm{w}}$. Combining the $\epsilon_{\mathrm{n}}=0.40 \mathrm{~m}$ and the standard deviation of the net balance $\sigma_{\mathrm{n}}=0.91$ in Equation (2) yields $r^{2}=0.81$. The two balance components $b_{\mathrm{s}}$ and $b_{\mathrm{w}}$ are positively correlated $(r=+0.21)$, which is thought to result from high albedo persisting longer into the ablation season following heavy winter accumulation, rather than from correlation between winter and summer meteorological conditions.

\section{TRENDS}

Discontinuities in South Cascade Glacier summer balance $b_{\mathrm{s}}$, temperature at $2000 \mathrm{~m}$ at the gridpoint, and snow flux $\bar{f}$ calculated at $1650 \mathrm{~m}$ (Equation (3)) all occur between 1986 and 1987 (Fig. 5). Hodge and others (1998) showed the 1986/87 discontinuity in $b_{\mathrm{s}}$ to be significant at the 0.01 level according to four statistical tests. Summer snow flux $\bar{f}$ decreased $33 \%$ from 0.42 to $0.28 \mathrm{~m} \mathrm{~s}^{-1}$, due in almost equal parts to drying and warming; that is, a decrease in the total amount of moisture reaching the glacier and in the part of it occurring below $+2^{\circ} \mathrm{C}$ at $1650 \mathrm{~m}$. This trend is also evident in the mean May-

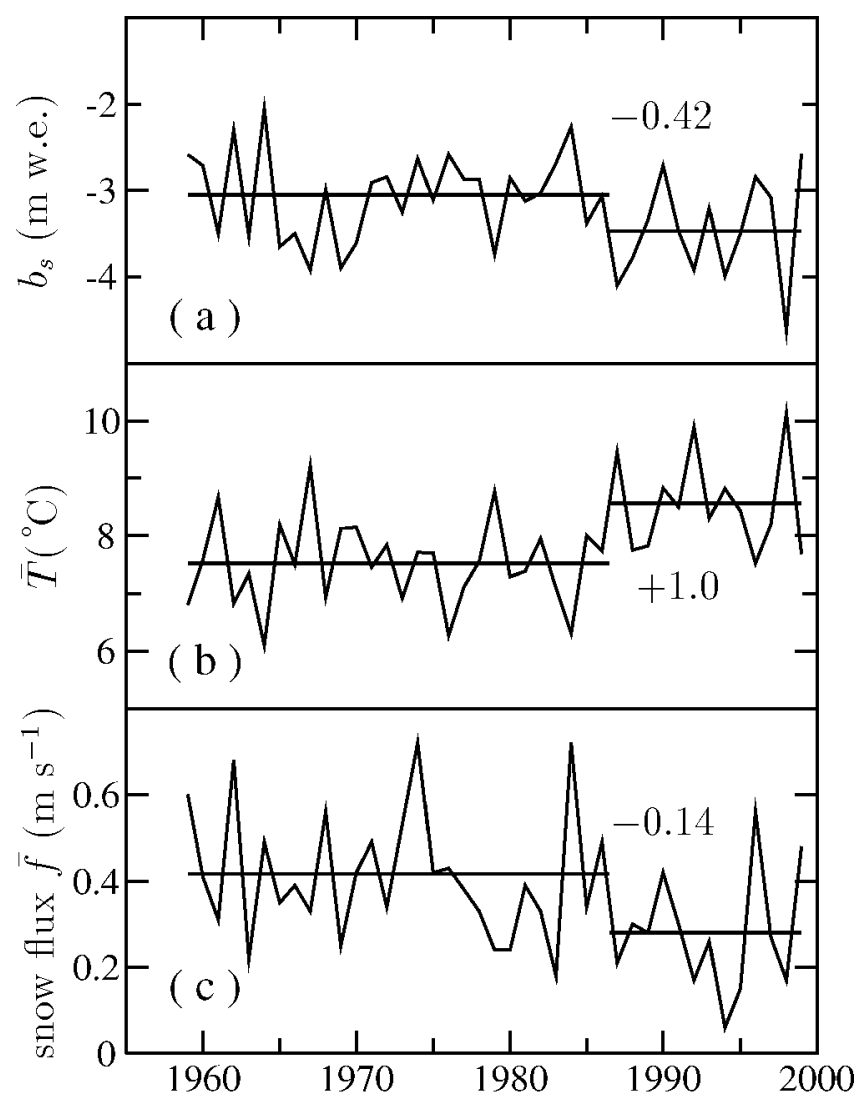

Fig. 5. Variations of summer balance, temperature and snow flux over 1959-99. (a) South Cascade Glacier summer balance $b_{\mathrm{s}} ;(b)$ average temperature $\bar{T}_{\mathrm{ELA}} ;(c)$ average snow flux $\bar{f}$ at $1650 \mathrm{~m}$. Averaging period for $T$ and $f$ is 26 April -4 October. Time of discontinuity between the two stages of the best-fitting piecewise-constant function is determined empirically, the best-fitting constant in a stage being the mean of the values in that stage. For each series the discontinuity is between 1986 and 1987, with the magnitude of the discontinuity shown in the figure.

September precipitation at Diablo Dam, which decreased $17 \%$ from $340 \mathrm{~mm}$ over $1959-86$ to $280 \mathrm{~mm}$ over $1987-99$.

Trends are expressed here in terms of a step discontinuity superposed on a time series assumed to be stationary both in the stage before the discontinuity and in the stage after it. The best-fitting constant in a stage is the mean of the values in that stage, and the time of discontinuity between one stage and the next is determined empirically to give the best fit overall. Time series approximated by two-stage piecewiseconstant functions over 1958-99 can be interpreted as a section of five-stage functions fit to several climatological variables in the North Pacific from 1870 to 1990 (Minobe, 1997, fig. 1c). Linear fits to the series in Figure 5 have slopes indicating annual rates of change $-0.011 \mathrm{~m}$ for summer balance, $+0.032^{\circ} \mathrm{C}$ for $2000 \mathrm{~m}$ temperature and $-0.005 \mathrm{~m} \mathrm{~s}^{-1}$ for snow flux; in all three cases the piecewise-constant fits explain more of the variance in the time series than the linear fits do.

Sensitivity to temperature is given by the $T$ model (Equation (1)) as $\partial b_{\mathrm{s}} / \partial T=\alpha_{1}=-0.50 \mathrm{~m}^{\circ} \mathrm{C}^{-1}$. The $T, f$ model gives a similar result; upon differentiating Equation (5), assuming the perturbation is the same at all altitudes,

$$
\begin{aligned}
\partial b_{\mathrm{s}} / \partial T & =\alpha_{2}+\beta_{2}(\partial \bar{f} / \partial T) \\
& =-0.39+[1.27(-0.092)]=-0.51 .
\end{aligned}
$$

The derivative $\partial \bar{f} / \partial T$ is determined by calculating $f$ when 
setting the rain-snow discriminator to $+1^{\circ} \mathrm{C}$ instead of $+2^{\circ} \mathrm{C}$ while holding all other model parameters constant. This summer sensitivity compares with $0.3-0.5 \mathrm{~m}^{\circ} \mathrm{C}^{-1}$ shown by the crosses in figure 3 of Oerlemans and Fortuin (1992) for 12 selected glaciers.

The summer sensitivity consists of $-0.39 \mathrm{~m}^{\circ} \mathrm{C}^{-1}$ due to enhanced ablation, and $-0.12 \mathrm{~m}^{\circ} \mathrm{C}^{-1}$ due to reduced accumulation (Equation (6)). Combining these with $-0.24 \mathrm{~m}^{\circ} \mathrm{C}^{-1}$ calculated for winter, which is mainly accumulation, shows that the sensitivities of annual accumulation $\left(-0.36 \mathrm{~m}^{\circ} \mathrm{C}^{-1}\right)$ and annual ablation $\left(-0.39 \mathrm{~m}^{\circ} \mathrm{C}^{-1}\right)$ are nearly equal. A slightly lower sensitivity $\left(-0.30 \mathrm{~m}^{\circ} \mathrm{C}^{-1}\right)$ of annual accumulation was estimated in section 4 of Rasmussen and others (2000) at Blue Glacier, which is $200 \mathrm{~km}$ to the west-southwest with about one-third greater accumulation.

Uniform warming of $1{ }^{\circ} \mathrm{C}$ through the year at all altitudes at South Cascade Glacier would make $b_{\mathrm{w}}$ less positive by $0.24 \mathrm{~m}$ and $b_{\mathrm{s}}$ more negative by $0.51 \mathrm{~m}$, for a total decrease in $b_{\mathrm{n}}$ of $0.75 \mathrm{~m}$. The $0.75 \mathrm{~m}^{\circ} \mathrm{C}^{-1}$ sensitivity nearly coincides with the $0.78 \mathrm{~m}^{\circ} \mathrm{C}^{-1}$ calculated for South Cascade Glacier by R. J. Braithwaite (personal communication, 2003), who also found this weak variation with altitude at South Cascade Glacier. The weak variation may not exist at glaciers with large vertical ranges.

Vertical profiles $b_{\mathrm{n}}(z)$ for each year 1986-98 have two significant features. The profile for each year is given in Krimmel (2000, 2001), or in reports for individual years cited in Krimmel (2001). The 13 year mean value of $b_{\mathrm{n}}$ at the top of the glacier was only $\approx+0.5 \mathrm{~m}$, and in four years $(1986,1987,1992,1998)$ $b_{\mathrm{n}}(z)$ was negative over the entire altitude range of the glacier, as it was again in 2001 (Krimmel, 2002). Thus, in a climate similar to $1986-98$ except for being warmer by $\approx 0.7^{\circ} \mathrm{C}$, the mean $b_{\mathrm{n}}(z)$ would be negative over the entire altitude range because $0.7^{\circ} \mathrm{C} \times 0.75 \mathrm{~m}^{\circ} \mathrm{C}^{-1}>0.5 \mathrm{~m}$. This inference assumes future $b_{\mathrm{n}}(z)$ would differ from the average profile over 198698 by a constant amount $\Delta b$ at all $z$, which is consistent with the assumption of weak variation with altitude of the sensitivity to temperature perturbations. It was shown in section 4.2 of Rasmussen and Conway (2001) to distinguish the profiles for individual years better than adjusting the profiles by an altitude increment; that is, using $b_{\mathrm{n}}(z+\Delta z)$. The glacier would probably then shrink to a narrow strip along the shaded western edge of the upper part of the glacier, which is the only place where 2000/01 accumulation survived after the $2001 \mathrm{ab}-$ lation season (Krimmel, 2002, fig. 14). Profiles $b(z)$ are widthaveraged at each $z$, which is the reason $b_{\mathrm{n}}$ can be positive in some places even when $b_{\mathrm{n}}(z)$ is negative over the entire altitude range.

\section{DISGUSSION AND SUMMARY}

The most significant result of the analysis is discovering how valuable the upper-air data are. The summer balance model has been tested and applied to Wolverine and Gulkana Glaciers, Alaska, U.S.A., over 1966-99 and Place Glacier, western Canada, over 1965-95. The resulting $r^{2}$ were, respectively, 0.55, 0.65 and 0.53, compared with 0.71 at South Cascade Glacier found in this study. It is remarkable that such a simple model does so well. Upper-air conditions must have a profound and direct effect on glacier mass balance; for both summer and winter mass balance, model errors are comparable to measurement errors. Success of the models depends on optimizing their parameters from balance measure- ments and using a temporal resolution that is sufficient to capture the non-linearities in relations between meteorological conditions and accumulation and ablation.

Oerlemans and Reichert (2000) used three different types of data to model the net balance for Nigardsbreen, in a maritime setting in Norway. Results using data from a distant lowland station (Bergen) gave $r=0.65$; monthly mean data from three nearby weather stations gave $r=0.76$; re-analysis data from the European Centre for Medium-Range Weather Forecasts gave $r=0.85$, which is slightly lower than $r=0.90$ found for South Cascade Glacier in this study.

Meteorological data cannot substitute for glacier measurements, because a balance record is needed to calibrate the model. Nevertheless in the absence of a glacier record, the model can be used to give a qualitative indication of relative balance changes. Taking the critical direction $\phi^{\prime}$ to be in the onshore direction, and interpolating temperature at the altitudes of the equilibrium line and the terminus will probably give results similar to those produced by the optimum values for those model parameters.

The two models could be used to extend the South Cascade Glacier mass-balance series back to 1948, when regular upper-air measurements began, provided major data inhomogeneities in early years can be mitigated. For example, it is not clear whether the apparent jump of $\approx 1.5^{\circ} \mathrm{C}$ in the upper-air temperature record in the late 1950 s is real or whether it is an artifact of sensor changes. The International Geophysical Year (1957/58) inspired increases in the quantity and quality of radiosonde measurements, and observation times changed on 1 June 1957 from 0300 and 1500 UTC, to 0000 and 1200 UTC (Angell, 1988; Kistler and others, 2001). The history of making and recording radiosonde temperature observations is detailed by Gaffen (1994), and a brief summary of inhomogeneities in the humidity record is given in Rasmussen and others (2001, section 4).

The models could also be used to predict how mass balance might change under possible future climate scenarios, such as from global circulation models. In the absence of change to either precipitation or atmospheric transmittance, a $1{ }^{\circ} \mathrm{C}$ warming would make $b_{\mathrm{s}}$ more negative by $0.51 \mathrm{~m}$ and $b_{\mathrm{w}}$ less positive by $0.24 \mathrm{~m}$. The net balance of South Cascade Glacier would decrease by $0.75 \mathrm{~m}$, which would overcome the 1986-98 average net balance of $+0.5 \mathrm{~m}$ at the top of the glacier.

\section{ACKNOWLEDGEMENTS}

This work was funded from the U.S. National Science Foundation grant OPP-0240861 and NASA grant 1215388. It was possible because of the accomplishment of U.S. Geological Survey researchers in operating the South Cascade Glacier program, principally M. F. Meier, A. S. Post, W.V. Tangborn and R. M. Krimmel, and because of Krimmel's superb documentation of measurements made. Comments by R. Braithwaite, by an anonymous reviewer and by scientific editor $\mathrm{R}$. Naruse have all produced many improvements in the paper. We thank E. Recker for extracting the re-analysis data from NCAR.

\section{REFERENGES}

Angell, J. K. 1988. Variations and trends in tropospheric and stratospheric global temperatures, 1958-87. f. Climate, 1(12), 1296-1313. 
Bevington, P. R. 1969. Data reduction and error analysis for the physical sciences. New York, McGraw-Hill.

Braithwaite, R.J. 1986. Assessment of mass-balance variations within a sparse stake network, Qamanârssûp sermia, West Greenland. F. Glaciol., 32(110), 50-53.

Braithwaite, R. J. and Y. Zhang. 2000. Sensitivity of mass balance of five Swiss glaciers to temperature changes assessed by tuning a degree-day model. 7. Glaciol., 46(152), 7-14.

Conway, H., L. A. Rasmussen and P. Hayes. 1995. On the use of radiosondes to model glacier ablation. Ann. Glaciol., 21, 245-250.

Elsberg, D. H., W. D. Harrison, K. A. Echelmeyer and R. M. Krimmel. 2001. Quantifying the effects of climate and surface change on glacier mass balance. 7. Glaciol., 47(159), 649-658.

Gaffen, D. J. 1994. Temporal inhomogeneities in radiosonde temperature records. 7. Geophys. Res., 99(D2), 3667-3676.

Hayes, P. S., L. A. Rasmussen and H. Conway. 2002. Estimating precipitation in the central Cascades of Washington. F. Hydrometeorol., 3 (3), 335-346.

Hodge, S. M., D. C. Trabant, R. M. Krimmel, T. A. Heinrichs, R. S. March and E. G. Josberger. 1998. Climate variations and changes in mass of three glaciers in western North America. 7. Climate, 11 (9), 2161-2179.

Kalnay, E. and 21 others. 1996. The NCEP/NCAR 40 -year reanalysis project. Bull. Am. Meteorol. Soc., 77(3), 437-471.

Kistler, R. and 12 others. 2001. The NCEP/NCAR 50-year reanalysis: monthly means CD-ROM and documentation. Bull. Am. Meteorol. Soc., 82(2), 427-467.

Krimmel, R. M. 2000. Water, ice, meteorological and speed measurements at South Cascade Glacier, Washington, 1986-1991 balance years. U.S. Geol. Surv. Water-Resour. Invest. Rep. 00-4006.

Krimmel, R. M. 2001. Water, ice, meteorological, and speed measurements at South Cascade Glacier, Washing ton, 1999 balance year. U.S. Geol. Surv. Water-Resour. Invest. Rep. 00-4625.

Krimmel, R. M. 2002. Water, ice and meteorological measurements at South Cascade Glacier, Washington, 2000-01 balance years. U.S. Geol. Surv. Water-Resour. Invest. Rep. 02-4165.

Miller, C. D. 1969. Chronology of Neoglacial moraines in the Dome Peak area, North Cascade Range, Washington. Arct. Alp. Res., 1(1), 49-66.

Minobe, S. 1997. A 50-70 year climatic oscillation over the North Pacific and North America. Geophys. Res. Lett., 24(6), 683-686.

Oerlemans, J. 2000. Analysis of a 3 year meteorological record from the ablation zone of Morteratschgletscher, Switzerland: energy and mass balance. 7. Glaciol., 46(155), 571-579.

Oerlemans, J. and J. P. F. Fortuin. 1992. Sensitivity of glaciers and small ice caps to greenhouse warming. Science, 258(5079), 115-117.

Oerlemans, J. and B. K. Reichert. 2000. Relating glacier mass balance to meteorological data by using a seasonal sensitivity characteristic. F. Glaciol., 46(152), 1-6.
Rasmussen, L. A. and H. Conway. 2001. Estimating South Cascade Glacier (Washing ton, U.S.A.) mass balance from a distant radiosonde and comparison with Blue Glacier. F. Glaciol., 47(159), 579-588.

Rasmussen, L. A., H. Conway and P. S. Hayes. 2000. The accumulation regime of Blue Glacier, U.S.A., 1914-96. F. Glaciol., 46(153), 326-334.

Rasmussen, L. A., H. Conway and P. S. Hayes. 2001. Estimating Olympic Peninsula precipitation from upper-air wind and humidity. 7 . Geophys. Res., 106(D2), 1493-1501.

Rhea, J. O. 1978. Orographic precipitation model for hydrometeorological use. (Ph.D. thesis, Colorado State University.)

Torinesi, O., A. Letréguilly and F. Valla. 2002. A century reconstruction of the mass balance of Glacier de Sarennes, French Alps. F. Glaciol., 48(160), $142-148$.

United States Navy. 1966. Selected level temperatures and dew points for the Northern Hemisphere. Washington, DC, U.S. Navy. Chief of Naval Operations. (Document NAVAIR 50-1C-52.)

\section{APPENDIX}

When the $T$ model (Equation (1)) was calibrated on only even-numbered years, the optimum averaging interval $\left[t_{0}, t_{1}\right]$ was days 117-283; it had $\epsilon_{\mathrm{S}}=0.35$ and $r^{2}=0.60$ when applied to the entire period 1959-99. When it was calibrated on only odd-numbered years over the same period, it was days 116-272; it had $\epsilon_{\mathrm{S}}=0.34$ and $r^{2}=0.62$. When it was calibrated on all years, $\left[t_{0}, t_{1}\right]$ was days $116-277$; over the early period 1959-86 it had $\epsilon_{\mathrm{s}}=0.28$ and $r^{2}=0.66$ and over $1987-99$ it had $\epsilon_{\mathrm{S}}=0.38$ and $r^{2}=0.56$.

In the $T, f$ model (Equation (5)), the averaging interval $\left[t_{0}, t_{1}\right]$ was fixed at the optimum from the $T$ model, and the critical direction $\phi^{\prime}$ for computing the flux $f$ was fixed at the optimum $271^{\circ}$ from the winter balance model. When calibrated on only even-numbered years, it had $\epsilon_{\mathrm{S}}=0.30$ and $r^{2}=0.70$ when applied to the entire period 1959-99. When calibrated on only odd-numbered years over the same period, it had $\epsilon_{\mathrm{S}}=0.31$ and $r^{2}=0.69$. When it was calibrated on all years, over 1959-86 it had $\epsilon_{\mathrm{s}}=0.27$ and $r^{2}=$ 0.69 and over 1987-99 it had $\epsilon_{\mathrm{s}}=0.35$ and $r^{2}=0.64$. 